FORMATION Formation emploi

Revue française de sciences sociales

117 | janvier-mars 2012

Enseignement supérieur : les défis de la professionnalisation

\title{
Pas de simplisme face à des professionnalisations plurielles
}

Jean-Frédéric Vergnies

\section{(2) OpenEdition}

Journals

Édition électronique

URL : http://journals.openedition.org/formationemploi/3507

DOI : 10.4000/formationemploi.3507

ISSN : 2107-0946

Éditeur

La Documentation française

Édition imprimée

Date de publication : 23 avril 2012

ISSN : 0759-6340

Référence électronique

Jean-Frédéric Vergnies, «Pas de simplisme face à des professionnalisations plurielles », Formation emploi [En ligne], 117 | janvier-mars 2012, mis en ligne le 06 juin 2012, consulté le 30 octobre 2020. URL : http://journals.openedition.org/formationemploi/3507 ; DOI : https://doi.org/10.4000/ formationemploi.3507 


\title{
Pas de simplisme face à des professionnalisations plurielles
}

\author{
Jean-Frédéric VERGNIES \\ Rédacteur en chef
}

\begin{abstract}
Ce dossier dédié à l'insertion professionnelle dans l'enseignement supérieur est l'occasion de s'interroger sur les multiples facettes de la professionnalisation, ce qui nous invite à la décliner au pluriel.

L'avènement de professionnels compétents, efficaces, responsables et autonomes met en jeu plusieurs mouvements de professionnalisations.

Une " professionnalisation-formation ${ }^{1}$ " qui procède de l'articulation entre formation et situations professionnelles. Une "professionnalisation-profession ", où une profession délimite ici son périmètre dans l'espace social et marchand (professions libérales, corps d'Etat...). Une " professionnalisation-travail » qui renvoie au développement des compétences permettant d'assurer l'adaptabilité-flexibilité-responsabilité des individus au sein de l'entreprise.
\end{abstract}

Comment choisir une formation professionnelle ? C'est la première question des jeunes et de leur famille. Utiliser un classement des établissements de l'enseignement supérieur selon un indicateur d'insertion professionnelle semble un bon élément de réponse. J. Bourdon, J.-F. Giret et M. Goudard, montrent néanmoins combien il est difficile de hiérarchiser les établissements, notamment en raison de la diversité de leurs étudiants et des formations dispensées.

De plus, D. Epiphane et J. Calmand nous rappellent que l'origine sociale pèse sur le devenir professionnel des jeunes, et ce quel que soit le caractère professionnalisant de la formation suivie.

1. On reprend ici la typologie proposée par R. Wittorski dans « Professionnaliser la formation : enjeux, modalités, difficultés ", Formation Emploi, n¹01, janvier-mars 2008 : Regards croisés sur les relations formation-emploi. 
Le stage serait-il alors le sésame pour un avenir professionnalisant en compensant le déficit de capital social des parents? Selon, J.-F. Giret et S. Issehnane, tous les stages ne se valent pas, le rôle de l'établissement et son prestige restent déterminants.

Rapprocher encore plus temps de formation et temps en entreprise serait alors la solution ? Cela apparaît à la fois prometteur et limité. En analysant le secteur stratégique de la recherche-développement, C. Bonnard montre que certains doctorants parviennent à valoriser leurs compétences dans ce secteur. Pourtant, cette solution reste limitée, à l'instar de nombre de conventions Ciffre pour les doctorants (moins de 700 entreprises financent de tels dispositifs chaque année ${ }^{2}$ ). Plus largement, la faiblesse du nombre de places en alternance ou en apprentissage perdure, malgré les injonctions régulières à leur croissance.

Au-delà, développer ses compétences ne dépend-il pas également des entreprises et de leur capacité à accueillir des jeunes et à développer leurs professionnalisations ? N. Moncel montre que les jeunes débutants sont confrontés à des segments différenciés du système d'emploi. Ainsi, aux deux extrêmes, certains font plutôt face à une précarisation " déprofessionnalisante " (30\%) tandis que d'autres bénéficient d'une insertion professionnalisante dans la stabilité ( $25 \%)$.

À la lecture de ce dossier, les professionnalisations se déclinent bien au pluriel. Elles dépendent autant de l'individu que du contexte et de l'organisation, que ce soit en matière d'information en fonction de la capacité des individus à choisir et s'orienter, et donc de l'entourage familial et social ; des possibilités offertes par les établissements de formation et les entreprises, notamment à travers les stages, ou les formations en alternance ; ou en termes de différents segments du marché de l'emploi.

En contrepoint, dans sa postface, M.-L. Favre-Bonnet souligne combien, face à la diversité des étudiants, il est essentiel pour professionnaliser les formations de l'enseignement supérieur, de se préoccuper aussi de la professionnalisation des enseignants du supérieur.

Bonne lecture à tous.

2. $C f$. www.enseignementsup-recherche.gouv.fr pour de plus amples informations sur les conventions industrielles de formation par la recherche (Ciffre). 